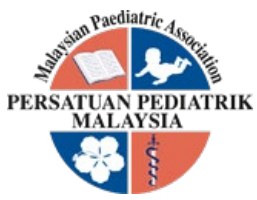

\title{
THE 'MORAL' PANDEMIC AND SOCIAL IMPACT ON CHILDREN IN MALAYSIA FOLLOWING COVID-19 PANDEMIC
}

\author{
Intan Juliana Abd Hamid', Fahisham Taib ${ }^{2,3}$, Mohd Ikram Ilias $^{2,3}$, Mohd Rizal Mohd Zain $^{2,3}$ \\ DOI: $10.51407 /$ mjpch.v27i2.191 \\ Received: 02 November 2021; Accepted revised manuscript: 05 December 2021 \\ Published online: 06 December 2021
}

\begin{abstract}
Introduction
COVID-19 pandemic has affected children in several ways resulting in various psychological and mental health consequences. The pandemic has not only affected the psychosocial concerns but has also distanced our connections among fellow human beings. Humans live together in a community or society to ensure each other's survival and improve livelihood. With the pandemic, the world population is forced to adapt to the new norms such as social distancing and wearing masks. While these regulations were imposed to reduce the risk of disease transmission, it has indirectly affected the daily interaction of people with each other. Even children must adhere to these preventive measures on a day-to-day basis during schooling, physical activities, and social gatherings. As a result, the long term consequences of the current pandemic are enormous and immeasurable.
\end{abstract}

Social distancing and movement control order are some of the important measures designed to mitigate the outbreak. However, this move has resulted, in an indirect 'moral' pandemic due to the fear and concern of COVID-19 transmission and infection. Children are advised to abide by social distancing ruling and avoid community or group gatherings and interactions. Moral pandemic refers to changes in usual practices affected by the stigmatisation of COVID-19 pandemic and psychological distance practice in a population leading to tension, judicious and suspicious behaviours. There will be a reduction in good samaritan acts, as the uneasiness in the current pandemic may detach one from being unbiased. Fewer humanization behaviours are caused by pandemic fear, which is worsened by deep political division causing relationship and emotional distance and hence leading to social fragmentation [1]. There is a pandemic uncertainty related to pandemic trajectory. For vulnerable children, it may result in stigmatization due to the presence of hierarchical social status, racial and ethnic differences. Undocumented children may be viewed as having less "value" because of their social background, resulting in societal tension, hatred, and animosity. Individual disparities in children's vulnerability would lead to stigmatisation of pandemic illness and secondary trauma experiences. This has become a moral crisis for humanity. Furthermore, another related issues of increased violence against women and girls during COVID-19 especially domestic violence have been reported and given the term of 'shadow pandemic'.

\section{Social impact from pandemic}

There are many studies relating pandemics to the risks of children experiencing maltreatment and

\footnotetext{
'Primary Immunodeficiency Diseases Group, Cluster of Regenerative Medicine, Advanced Medical and Dental Institute (AMDI), Universiti Sains Malaysia, 13200, Kepala Batas, Pulau Pinang, Malaysia

2Paediatric Department, Hospital Universiti Sains Malaysia, 16150 Kota Bahru, Kelantan, Malaysia

${ }^{3}$ Paediatric Department, School of Medical Sciences, Universiti Sains Malaysia, 16150 Kota Bahru, Kelantan, Malaysia.

Corresponding Author:

Dr. Fahisham Taib, Paediatric Department, School of Medical Sciences,

Universiti Sains Malaysia,16150 Kubang Kerian, Kelantan, Malaysia

Tel.: +607676515 Email: fahisham@usm.my
} 
violence at home [2]. Children who are from lower socio-economic group families are deprived of poor nutrition, academic access, and neglect of care. The lockdown measures have reduced opportunities for children to participate in extra circular activities, to meet with peers and supportive adults at school and even face-to-face learning in the classroom. The school environment shapes children in many aspects related to social interaction and skills with peers. This is vital for psychological and emotional development. The impact of digital learning and online classes posed a challenging avenue for education and learning [3]. There is disparity among the group of children where allocation for the disadvantaged population such as refugee, migrant and undocumented children have been scarce despite their health and medical rights. This would affect the literacy rate and even academic performance in the future [3]. Children from lower social-economic groups may not have access to online learning and even computers or mobile device. Many of the reproductive age group parents have lost jobs due to strict lockdown rules. Their focus is on daily survival rather than vaccination. Furthermore, vaccination uptake among these groups may also be affected posing a constant risk to COVID-19 infection. A recent cross-sectional study observed high rates of depression and anxiety among Malaysian families and children, where the job security of the family lead found to be a significant predictive factor [4].

There are many other groups of children such as children with disabilities, homeless and under foster care which should be monitored closely. They all possess the right to be at school, to have their health optimized and to have brighter access to education. Missing school may predispose to a decrease in physical activity, erratic sleep patterns, increased screen time and internet use, which may increase the risk of developing internet addiction, increased exposure to digital psychosocial threats such as cyberbullying, sedentary habits, and a poor quality of life, all of which may be associated with anxiety or depression.

\section{Invisible and long-term social consequences}

With over 200 coronavirus deaths per day in Malaysia, it is estimated that $30 \%$ of them are related to the reproductive and younger generations [5]. If the total number of deaths is 15,550 (as of 28 August 2021), approximately 5,000 adult parents will have died, leaving more than 5,000-10,000 children without one of the primary caregivers. This will be a significant burden to the society and Malaysian government. Eventually, the children will suffer from academic catch up, significant socioeconomic deficit and psychologically traumatic experiences. Globally, in a space of one year, an estimate of $1,134,000$ children experienced the death of primary caregivers, including at least one parent or custodial grandparent. Orphanhood and caregiver deaths are hidden consequences of a pandemic resulting from COVID-19 associated deaths [6]. Accelerating equitable vaccine delivery is key to prevention. Contextually, families in Malaysia would be able to survive with the support of extended family members. The psychosocial and economic support could help to avoid the institutionalisation of these children. However, the families who have lost a breadwinner would be plunged into deeper poverty and destitution. These heightened consequences were observed in developing countries [2]. Children are likely to have been directly exposed to social, economic and healthrelated anxieties. They have had to deal with the grief associated with illnesses or, ultimately, death within families while being unable to receive necessary support due to physical distancing.

\section{Rights of the undocumented children}

At this current state, there is no clear guideline on how to safeguard the undocumented children with COVID-19 [1]. Guideline from the Western countries argues on the respect for human rights and according to Hippocratic Oath. Malaysia is a country that did not ratify the recognition of refugee and undocumented children [1]. Anecdotally, undocumented and refugee children are becoming irrelevant to the mainstream in society. In Norway, $31 \%$ are foreign-born being infected with COVID-19 [7]. Immigrants and undocumented suffer a higher casualty due to higher infection risk and higher mortality. There are concerns related to protection from and prevention of abuse, neglect, discrimination, exploitation, and provision of assistance to support young people's basic needs [8]. Children's best interest is complex and should be incorporated with their shared perspectives 
and interests, if possible [2]. There are pockets of vulnerable children living more concentrated in Sabah and all over Peninsular Malaysia. Some are legal immigrants, and a substantial number are illegal. Some locals have no legal documents and are considered to be undocumented. They are deprived of health rights and even human rights as an individual [9]. For children, the situation is even more complicated because immigrant parents are afraid to bring their children to the hospital because they must pay higher hospital bills than Malaysians.

There is also the possibility of secondary trauma. Secondary traumatic stress is the emotional duress that results when an individual hears about the first-hand trauma experiences of another. Many refugee families avoided accessing Malaysian health care because of the fear of harassment, arrest, and detention from the authorities [1]. Its symptoms are very similar to those of post-traumatic stress disorder. Undocumented children who were admitted to the hospital either with the family or isolated may suffer this. In chaotic management and focus towards COVID-19 supportive care, this may be overlooked. Parents may be isolated in a single room, scared of being deported rather than the underlying disease and may be detained in the hospital set-up. These children may experience inappropriate care and separation anxiety from their parents. Logistically, it may not be possible to give the best possible treatment, however, improvement should be done towards respecting the rights of children irrespective of their social status. The guideline also should focus on family unity while respecting universal individual human rights - be treated with dignity, without distinction of race, colour, and political affiliation, avoiding degrading treatment without discrimination, and without arbitrary detention [10].

The human rights for refugees and undocumented children are difficult issues due to the deficient existence of standardized guidelines nationally. They are considered 'illegal immigrants' and have violated the immigration laws of the country [11]. They also technically do not possess any rights under Malaysian laws. However, a paradox to this, there are many reasons to extend health rights to non-citizens, especially children and pregnant women, in the light of moral, ethical, humanistic, religious, philosophical, and legal human rights justification [12]. Children and mothers are among the most vulnerable populations, and hence they deserve cost-effective preventive measures. Standard practice is to provide emergency life-saving measures with an appropriate guideline to ensure adequate medical care and respect their rights and dignity. Health professionals need not be responsible for reporting to the authority if undocumented migrants are under the hospital, to avoid a professional conflict of interest and respect individual confidentiality.

The course of the pandemic has affected the vulnerability of many undocumented and refugee populations as a result of the policy of exclusion. Serious policy and guidelines should include prevention and containment measures, establishing an inter-agency and inter-sectoral task force and providing access to immigrants with adequate delivery humanitarian aid and health care treatment [13].

\section{Conclusion}

Moral pandemic and social impacts on children in Malaysia would lead to enormous repercussions socially and psychologically. Vulnerable children need to be identified to ensure the rights of children are respected and children's right to education, health, protection, and development are fulfilled.

\section{References}

[1] Khoso, A., Hussin, H. Malaysia's Refugee and Asylum-Seeking Children: A Child Rights Perspective. Otoritas: Jurnal Ilmu Pemerintahan 2020; 10(2): 97-119. https://doi.org/10.26618/ojip.v10i2.4639

[2] Campbell S, Cicero Oneto C, Saini MPS, et al. Impacts of the COVID-19 pandemic on children: An ethical analysis with a globalchild lens. Global Studies of Childhood. 2021;11(1):105-114. https://doi.org/10.1177/2043610620976142

[3] Mohd Azahar NMZ, Ahmad Zaki MA, Devaraj NK. Health Consequences During Pandemic: A Review. Mal J Med Health Sci 2021; 17(3):295-302

[4] Zainudeen ZT, Abd Hamid IJ, Azizuddin MNA, et al. Psychosocial impact of COVID-19 pandemic on Malaysian families: 
a cross- sectional study. BMJ Open 2021;0:e050523. https://doi.org/10.1136/ bmjopen-2021-050523

[5] Death among 50-64 high. Accessed on $6^{\text {th }}$ of September 2021 from https://www.thestar.com.my/news/nation/20 21/05/15/death-among-50-to-64-high

[6] Hillis SD, Unwin HJT, Chen Y, Cluver L, Sherr L, Goldman PS, Ratmann O, Donnelly CA, Bhatt S, Villaveces A, Butchart A, Bachman G, Rawlings L, Green P, Nelson III CA, Flaxman S. Global minimum estimates of children affected by COVID-19-associated orphanhood and deaths of caregivers: a modelling study. Lancet 2021; 398: 391-402. https://doi.org/10.1016/S01406736(21)01253-8

[7] OECD (2020), "What is the impact of the COVID-19 pandemic on immigrants and their children?", OECD Policy Responses to Coronavirus (COVID-19), OECD Publishing, Paris, https://doi.org/10.1787/e7cbb7de-en

[8] Berman G. Ethical Considerations for Evidence Generation Involving Children on the COVID-19 Pandemic. Office of Research Innocenti Discussion Paper DP 2020-01 | April 2020

[9] Undocumented migrants and refugees in Malaysia: Raids, Detention and Discrimination. FIDH-SUARAM 2008

[10] Universal Declaration of Human Rights. Accessed on $6^{\text {th }}$ of September 2021 from https://www.un.org/en/about-us/universaldeclaration-of-human-rights

[11] Khairi A. Managing the Challenges of Refugees and their Rights in Malaysia. Accessed on $6^{\text {th }}$ of September 2021 from https://media.neliti.com/media/publications/ 132161-EN-managing-the-challenges-ofrefugees-and.pdf

[12] Proposing a Non-Citizens Health Act for Malaysia. Accessed on $6^{\text {th }}$ of September 2021 from https://www.thestar.com.my/opinion/letters/ 2020/01/11/proposing-a-non-citizens-healthact-for-malaysia

[13] Wahab A. The outbreak of Covid-19 in Malaysia: Pushing migrant workers at the margin. Social Sciences \& Humanities Open. 2020; 2(1):100073. https://doi.org/10.1016/j.ssaho.2020.100073. 